\title{
TWO-MACHINE ROBOTIC CELL SEQUENCING UNDER DIFFERENT UNCERTAINTIES
}

\author{
Vaisi, B. ${ }^{*}$; Farughi, H. ${ }^{* *}, \#$ \& Raissi, S. \\ * School of Industrial Engineering, South Tehran Branch, Islamic Azad University, Tehran, Iran \\ ** Department of Engineering, University of Kurdistan, Sanandaj, Iran \\ E-Mail: st_b_vaisi@azad.ac.ir, h.farughi@uok.ac.ir, Raissi@azad.ac.ir ( ${ }^{\#}$ Corresponding author)
}

\begin{abstract}
Currently, robotic manufacturing cells entail complex decisions concerning sequencing issues due to uncertainty which arises in different parameters such as time to failure, time to repair and cycle times that can be effectively supported by computer simulation models. The paper is focused on part sequencing of a two-machine robotic cell in a flow shop which produces different parts. The process is supported by a single gripper robot to load/unload products and also in displacement within the system. This study considers machine failures and repair such that $S_{2}$ cycle time and total production cost should be minimized. In this study, simulation facilitated input part sequence and also data envelopment analysis method is applied to trace the optimum sequence for satisfying the objective functions. Results through some numerical examples showed some simulation advantages specially to model many uncertainties and what if analysis.

(Received in November 2017, accepted in April 2018. This paper was with the authors 2 weeks for 1 revision.)
\end{abstract}

Key Words: Robotic Manufacturing Cell, Sequencing, Breakdowns, Multiple Part Type Production, Simulation, Data Envelopment Analysis

\section{INTRODUCTION}

A typical flexible manufacturing system (FMS) consists of robots, computer numerical controlled machines (CNC) and other relevant stand-alone systems such as inspection machines, instrumentation devices, computers and sensors. Here, robot has responsibility of picking-up products, loading and unloading machines and also material displacement operations within the cell. Applying robots facilitate the process and promote system productivity. Hence, all finished products will be transferred to an automatic inspection node at the last stage.

Numerous researchers have focused on sequencing of machine feedings and robot moves in a robotic cell to promote total system productivity. Due to the avoidance of complexity that arises in mathematical modelling, machine breakdowns and transportation times so far have relaxed on scheduling and sequencing optimization process, although this may lead to change the optimal solutions. Also, optimization using a single criterion could not address the real management objectives.

A survey of the most important results on multi criteria scheduling appeared in [1]. Multi objective optimization of a FMS was done recently based on a modified NSGA-II algorithm [2]. Generally, cycle time is defined as the standard time for processing a part at a system [3]. A bi-criteria scheduling model that jointly minimize the cycle time and the total manufacturing cost in a robotic cell of two identical $\mathrm{CNC}$ machines producing identical parts was presented by [4]. They asserted that manufacturing costs for the first time is being considered as an objective function. The reader is referred to [5-7] for studying other papers concerning bi objective problems in the field of robotic manufacturing cell scheduling.

In most previous researches conducted in the field of robotic manufacturing cells, scheduling is done based on a single criterion, minimizing cycle time or maximizing the output rate of the cell, such as referred in papers [8-12]. In another new paper, unavailability 
periods resulting from lunch and tea breaks are considered in a fully automated robotic spot welding line, when tool life related constraints are added. Their mathematical model tried to overlap unavailability periods with tool changes periods [13].

From the point of view of part type, in different-part types, determining the part input sequence is the main issue. There are several studies on the sequencing of parts in robotic manufacturing cells reported in the literature. In some of them, the problem was solved based on the known Gilmore and Gomory algorithm, such as in $[14,15]$ and in some others the problem was formulated based on TSP problem, such as in $[8,16,17]$. In studies conducted by [18-23] heuristics or some special algorithms were employed to solve the problem. In a new study a metaheuristic approach with simulated annealing tool was applied to schedule a two machine robotic cell. In this manufacturing cell, processing time of the parts on the machines is not constant [24]. In none of the previous studies simulation based optimization is applied to solve the problem of determining part input sequence to the machines.

In most industrial atmospheres, it is required to perform different tasks during a particular time interval, deterioration and stoppage between these tasks impose huge costs, this leads to attention to maintenance. There are very limited studies in the field of maintenance and reliability assessment on robotic manufacturing systems, which none of them is specifically associated with the robotic manufacturing cell, such as $[25,26]$.

One of the most frequent assumptions in modelling of such systems is on relaxing random variables such as machine processing times; part number arrival rates; item arrival rates at manufacturing cell and equipment's breakdown and repairing times. In order to overcome such deficiencies, some researchers applied the mean of relevant random variable in their model or alternatively, the long term modifying metrics such as availability measures. Due to the uncertainties arise in this context modelling, more realistic modelling approach has been on appeal.

The rest of the paper is structured as follows: In section 2, the problem definition and assumptions are presented. In order to overcome different uncertainty, a proposed computer simulation model is developed in section 3. In section 4, designated scenarios are given and through numerical examples a discussion based on optimal part input sequences is revealed. Finally, conclusion is presented in section 5.

\section{PROBLEM STATEMENT}

Suppose a common robotic industrial cell to deploy rapidly changing customer demands [25]. Application of a flexible system could reduce production cost and promote quality characteristics. Such cells consist of one or more machines, supported by a robot for loading, unloading and transferring of parts. A typical in-line two machine robotic cell is shown in Fig. 1.

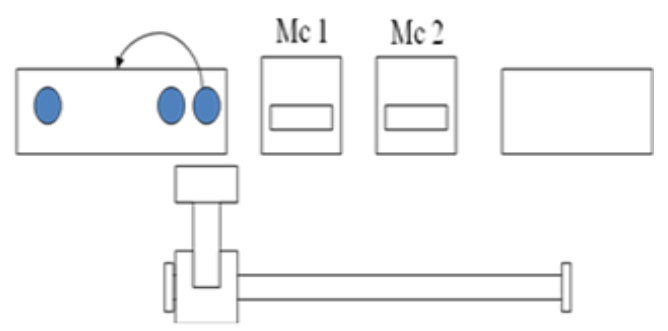

Figure 1: Typical layout for a 2-machine in-line robotic cell.

In the production system, there are two identical CNC machines without priority in operation. This implies that both machines are capable of performing the required operations at the same time. Loading and unloading of parts and also the displacement of raw material 
basket to the selected machine and from the machine to the products basket is done by a single gripper robot. Typically, in a 2-machine cell, three cycles, nominated as $S_{1}, S_{2}$ and $\mathrm{S}_{12} \mathrm{~S}_{21}$ cycles may be applied for part displacements. Here, we focused on the $\mathrm{S}_{2}$ cycle because it is a well-known and commonly used cycle, but less attention has been paid in the modelling due to more complexity than the others.

The general process of $S_{2}$ cycle in a 2 -machine cell is as follows. In the $S_{2}$ cycle, initially, robot takes place in front of the input buffer. Then the following operations are followed sequentially. 1) picking up a part by the robot, 2) moving to the $1^{\text {st }}$ machine, 3) loading the $1^{\text {st }}$ machine, 4) moving to the $2^{\text {nd }}$ machine, 5) waiting for completing the previous part process (if necessary), 6) unloading the part from the $2^{\text {nd }}$ machine, 7) moving the product to output buffer, 8) loading the output buffer, 9) moving to the $1^{\text {st }}$ machine, 10) if necessary waits until the completion of the process, 11) unloading from $1^{\text {st }}$ machine, 12) moving the part to the $2^{\text {nd }}$ machine, 13) loading the part on the $2^{\text {nd }}$ machine and finally 14) Turning back to the input buffer. As a well-known rule, the activity sequence of $\mathrm{S}_{2}$ cycle is coded by $A_{01} A_{23} A_{12}$ [27].

Considering $\mathrm{S}_{2}$ cycle time in [5], taking into account $a=b$ (because of the upcoming number 13 assumption in section 2.1) and positivity of $W$ values ( because of the considerable values of part's processing time than $\varepsilon$ and $\delta$ ), here the parameters' features are considered as comes in Table I.

Table I: The main problem parameters' features.

\begin{tabular}{|c|l|c|}
\hline Parameters & \multicolumn{1}{|c|}{ Expression } & Type \\
\hline$\varepsilon:$ & Loading/unloading time & Deterministic \\
\hline$\delta:$ & Time taken by a robot to move between two consecutive stations & Deterministic \\
\hline$T_{S_{2}}:$ & Cycle time based on $S_{2}$ robot move cycle & Stochastic \\
\hline$W_{i}:$ & Robot's waiting time in front of machine $i ; i=1, \ldots, n$ & Stochastic \\
\hline$A_{p q}:$ & $\begin{array}{l}\text { Robot activity sequence from station } p \text {, to station } q, \text { for: } \\
p=0,1,2 \text { and } q=1,2,3 .\end{array}$ & Deterministic \\
\hline$t_{i}:$ & Processing times of part $i ; i=1, \ldots, n$ & Deterministic \\
\hline
\end{tabular}

Time scale is in minutes.

Hence the $S_{2}$ cycle and waiting times could be calculated by Eqs. (1) and (2) respectively.

$$
\begin{aligned}
& T_{S 2}=6 \varepsilon+8 \delta+W \\
& W=t_{i}-(2 \varepsilon+4 \delta)
\end{aligned}
$$

The main objective of this study is to determine the sequence of parts in an unreliable two machine robotic cell to minimize both the $S_{2}$ cycle time and total production cost. This robotic cell experiences random failure and repair times. Nevertheless, in the previous mathematical modelling approach, their random behaviour was not considered. Note that the waiting time in front of machine and also cycle time obey a stochastic manner due to the relevant dependencies.

Total production cost consisted of machining, tooling and preventive maintenance cost [28]. In many cases such as the present one, tooling cost is considered to be a constant value and has no effects on optimization process. In the mathematical model for calculating total production cost, the following parameters and variables are definite.

$C_{\mathrm{o}} \quad$ Machining cost $(\$ / \mathrm{min})$

$C_{P M} \quad$ Cost of a preventive maintenance (PM) visit (\$/visit): without considering any setup cost

$C_{\text {TOOL }}$ Cost of tool (\$/tool): Tools replacement prohibited in an operating cycle

$p_{j} \quad$ Expected down rate of machine $j$

$H \quad$ Observation period

$F \quad$ Total cost (\$/times unit) 
TTF Time to failure (times unit)

TTR Time to repair (times unit)

Accordingly, the total cost per operating cycle could be calculated by Eq. (3).

$$
F=2 \sum_{i=1}^{n} C_{o} t_{i}+\sum_{j=1}^{2} C_{P M} P_{j} H+C_{T O O L}
$$

\subsection{Assumptions}

The literature review reveals that scheduling of flexible manufacturing cells was commonly carried out in deterministic and little research has been done on this issue under stochastic conditions. We assumed that each machine has two states; up and down independent of each other and failure/repair rates might be constant or time dependent; $\lambda(t)$ and $\mu(t)$ respectively. If they are constant over time, one may consider that time to failure and repair time are deployed from an exponential distribution; otherwise an alternate distribution such as Weibull, Gamma or other density functions might be addressed for their modelling. We summarize the basic assumptions for the present study as follows.

1- Parts are always available at the input buffer and an empty place is always available at the output buffer.

2- The robotic manufacturing cell produces different part-types.

3- There is no buffer storage between the machines and each part is either on a machine or being handled by the robot.

4- Production runs continuously.

5- Setup times are assumed to be negligible.

6- No pre-emption is allowed in the processing of any operation.

7- The robot and the machines cannot be in possession of more than one part at any time.

8- In-line robotic cell exists including two machines and a single gripper robot.

9- Sequence of operations is followed through $S_{2}$ cycle for a 2-machines robotic manufacturing cell.

10- Machines experience random failure and require maintenance.

11- TTF and TTR follow any given statistical density function with known reliable parameters.

12- The processing time of each part on each machine, regardless of stops due to failure, etc., has been determined definitively, and the allocation of the required operations to produce each part in two machines is not discussed in this paper.

13- Producing each part requires a variety of operations to be processed on the machines, by default, some of which are done on the machine one and the rest is done on the machine two. (According to the existence of several scenarios in allocating the required operations to produce each part to the machines, it is assumed that the processing time of each part on both machines is equivalent.)

\subsection{Cases}

The applicability of simulation based optimization approach is examined by means of two different examples derived from previous work, [29]. In the below examples, each colour means one type part.

Example 1. Three different types of products to be manufactured with corresponding processing times: Blue (B): 57, Red (R): 84 and Purple (P): 87 minutes. Also $\varepsilon$ and $\delta$ respectively are 1 and 2 minutes.

Example 2. In a robotic cell six parts are produced with corresponding processing times: Purple (P): 97, Blue (B): 123, Red (R): 4, Green (G): 18, Yellow (Y): 20 and Silver (S): 26 minutes. Here, loading, unloading and robot transportation time takes 4 minutes long. 
Example 3. Assume a robotic cell for manufacturing a single product through processing time of 87 minutes for a Purple coloured product. Here $\varepsilon$ and $\delta$ are respectively 1 and 2 time units.

The parameters and the user defined values for the considered robotic cell are presented in Table II. It should be noted that the same tool is used for all of these operations and we assumed that these parameter values are constant.

Table II: Characteristics of required parameters.

\begin{tabular}{|c|c|c|}
\hline$C_{P M}=35$ & $C_{\mathrm{o}}=50$ & $C_{T O O L}=45$ \\
\hline$T T F=\operatorname{NegExp}(10)$ & $T T R=\operatorname{NegExp}(2)$ & \\
\hline
\end{tabular}

\section{SIMULATION MODEL DEVELOPMENT}

Nowadays, the robotic manufacturing cells entail complex decisions concerning sequencing issues due to uncertainty which arises in different parameters such as TTF, TTR and cycle times that can be effectively supported by computer simulation models. This method has been developed since the early 1960s and may well be the most commonly used of all the analytical tools of management science, [30]. In order to analyse the presented robotic cell, computer simulation was integrated with linear programing optimization approach to overcome different sources of uncertainties. The most important feature of this method can be seen in its high ability in coincidental examination of different random variables. The number of random variables or stochastic behaviour may vary in different cases. For example, in some cases, the role of the operators may be important in system performance or, in certain cases, the pre-emption in material flow or repairing is allowed. Considering uncertainty of the amount of arriving parts, sequencing of entering the parts or time to arrival of them beside randomly distributed set up time and cycle time also leads to a lot of complexity.

In this study, there is uncertainty in cycle time and robot's waiting time in front of machines. Here, producing different parts which means different sequencing patterns for entering parts to the robotic cell by considering stochastic breakdown in the machines, faces the robotic manufacturing cell with uncertainty.

It is very difficult to optimize such systems only by mathematical programing methods. In these cases, there is definitely no approach to help us effectively without applying computer simulation models. Even though simulation methods are known as descriptive modelling method, luckily changing the base computer model to be used for other cases is not considered as a complicated task to follow by conventional simulation experts.

For this purpose, the Enterprise Dynamics (ED) simulation tool is applied to model the sequence of parts in the considered robotic cell. This simulation package is enriched with a user friendly environment and utilizes from a drag and drop technology. A large stand-alone library helps users to pick up the most appropriate elements for modelling the desired layouts easily. In the literature, there are some studies on the use of simulation in manufacturing systems such as [31-34] and so on. Also, as an appropriate document in application category, a comprehensive review of articles involving simulation in manufacturing between 2002 and 2013 has been provided in [35].

Fig. 2 presents the layout of simulation model for the robotic cell. Hence, three distinct products flow within the system using the "Source" elements. Here, it is easy to model the time between the arrival of lots of different raw materials and their sizes based on any common density functions.

After generating the products, they are routed to a "Queue" to be loaded in one of the existing machines by the single griper robot based on the $S_{2}$ cycle in turn. In the simulation layout, a "Server" atom could be used to model the production operations. For modelling the 
robot tasks we proposed a "Transporter" atom. By placing an "Excel ActiveX" atom into the model, the link between our proposed ED model and excel workbook to export the results is organized. When the simulation is started, the "Status Monitor" and "Status Histogram" atoms will automatically begin to display the status statistics.

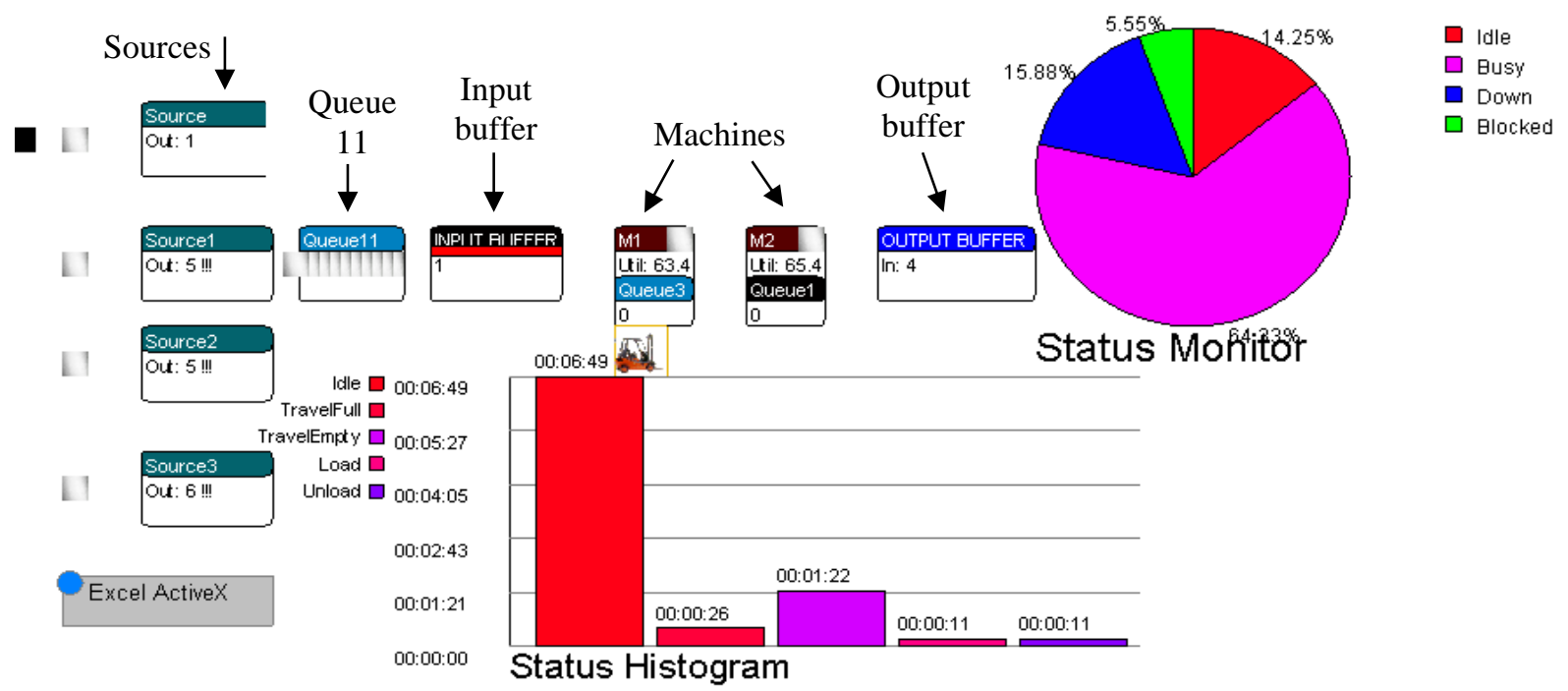

Figure 2: Simulation ED layout model for the 2-machine robotic cell.

We also defined an interface for connecting the simulation model with the Microsoft Excel to write different product outputs separately. In order to obtain unbiased estimates, in the experimental wizard setting, all simulation models run for a long time (more than 10000 hours) after a warm up period which took 50 hours. Also, three performance measures (PFM) are defined as follows.

$Y_{1}$ : The average time for each $S_{2}$ cycle in simulation period,

$Y_{2}$ : The average operating cost per each part in simulation period,

$Y_{3}$ : Number of throughout products in simulation period.

\section{RESULTS AND DISCUSSION}

\subsection{Simulation results}

First, we run the simulation model on Example 3, in the absence of machine failure. Based on our designed model, we conclude with a $95 \%$ confidence level that the average $\mathrm{S}_{2}$ cycle time and operating cost are 107.8795 and 190 , respectively, reported by $\mathrm{ED}^{\mathrm{TM}}$.

\subsection{Validation}

In order to examine simulation model validation, we applied the Mann-Whitney hypothesis testing method to compare statistical difference between the mean of daily production on the simulation model after replicating the model 25 times and real observed production (we called the results obtained from Eq. (1) as real results). Here, high $p$-value greater than 0.85 revealed that there is no significant difference to reject two means; therefore, we could not reject the simulation model validation.

Consequently, we design some scenarios to find the best sequence for parts interval in designated instances. We want to represent a new way other than pure mathematical modelling and heuristic solution to determine optimal sequence for entering different parts to a two-machine robotic cell having $S_{2}$ move cycle for robot. 


\subsection{Scenario design}

For designing scenarios, we consider some different sequences for parts interval, adjust each one as a scenario and run each scenario by means of ED software. The designated scenarios for intended Examples come in Table III. It should be noted that, we would obtain average $\mathrm{S}_{2}$ cycle time, average cost and number of produced throughput based on the adjusted simulation time. We want to obtain maximum throughput by minimum cost and minimum cycle time, so by setting throughput as the output of the system and both cost and cycle time as the inputs of the system we tried to model the data by applying Data Envelopment Analysis (DEA) method to find the best scenarios.

Then, based on the designated scenarios, we run the simulated model. The results according to the defined PFMs, are as follows in Table IV.

Table III: Designated scenarios for designated Examples.

\begin{tabular}{|c|c|c|c|c|c|c|c|c|c|}
\hline \multirow[t]{4}{*}{$\begin{array}{l}\text { EXAMPLE } \\
1\end{array}$} & \multicolumn{3}{|c|}{$\begin{array}{l}\text { Sequence } 1 \\
\text { B-R-P }\end{array}$} & \multicolumn{3}{|c|}{$\begin{array}{l}\text { Sequence } 2 \\
\text { B-P-R }\end{array}$} & \multicolumn{3}{|c|}{$\begin{array}{l}\text { Sequence } 3 \\
\text { P-R-B }\end{array}$} \\
\hline & \multicolumn{9}{|c|}{$\begin{array}{l}\text { The first allocated part to the } 2^{\text {nd }} \text { machine } \\
\text { Scenario number (Below) }\end{array}$} \\
\hline & B & $\mathrm{P}$ & $\mathrm{R}$ & $\mathrm{B}$ & $\mathrm{P}$ & $\mathrm{R}$ & $\mathrm{B}$ & $\mathrm{P}$ & $\mathrm{R}$ \\
\hline & 1 & 2 & 3 & 4 & 5 & 6 & 7 & 8 & 9 \\
\hline \multirow{9}{*}{$\begin{array}{l}\text { EXAMPLE } \\
\quad 2\end{array}$} & \multirow{3}{*}{\multicolumn{3}{|c|}{$\begin{array}{l}\text { Sequence: } \\
\text { (Seq. \#) }\end{array}$}} & \multicolumn{6}{|c|}{ The first allocated part to the $2^{\text {nd }}$ machine } \\
\hline & & & & $\mathrm{P}$ & B & $\mathrm{R}$ & $\mathrm{G}$ & $\mathrm{Y}$ & $\mathrm{S}$ \\
\hline & & & & \multicolumn{6}{|c|}{ Scenario Number } \\
\hline & \multicolumn{3}{|c|}{ Seq. 1: P-R-Y-B-G-S } & 1 & 2 & 3 & 4 & 5 & 6 \\
\hline & \multicolumn{3}{|c|}{ Seq. 2: P-Y-G-B-S-R } & 7 & 8 & 9 & 10 & 11 & 12 \\
\hline & \multicolumn{3}{|c|}{ Seq. 3: R-S-B-P-G-Y } & 13 & 14 & 15 & 16 & 17 & 18 \\
\hline & \multicolumn{3}{|c|}{ Seq. 4: B-Y-P-S-G-R } & 19 & 20 & 21 & 22 & 23 & 24 \\
\hline & \multirow{2}{*}{\multicolumn{3}{|c|}{ Seq. 5: R-G-Y-S-P-B }} & 25 & 26 & 27 & 28 & 29 & 30 \\
\hline & \multicolumn{2}{|c|}{ Seq. 6: B-P-S-Y-G-R } & & 31 & 32 & 33 & 34 & 35 & 36 \\
\hline
\end{tabular}

Table IV: Defined performance measure amounts of designated scenarios in considered Examples.

\begin{tabular}{|c|c|c|c|c|c|c|c|c|c|}
\hline \multirow{3}{*}{ EX. 1} & \multicolumn{3}{|c|}{ Seq.1 } & \multicolumn{3}{|c|}{ Seq. 2} & \multicolumn{3}{|c|}{ Seq. 3} \\
\hline & \multicolumn{9}{|c|}{ Scenario Number } \\
\hline & 1 & 2 & 3 & 4 & 5 & 6 & 7 & 8 & 9 \\
\hline$Y_{1}:$ & 143.570 & 143.486 & 123.53 & 123.418 & 130.41 & 123.419 & 123.479 & 123.504 & 123.473 \\
\hline$Y_{2}:$ & 39001.3 & 38978.8 & 33582.9 & 33551.7 & 38965. & 33551.7 & 33567.3 & 33571.7 & 33566.3 \\
\hline$Y_{3}:$ & 27582 & 27598 & 32055 & 32085 & 27605 & 32085 & 32070 & 32063 & 32071 \\
\hline \multirow[t]{2}{*}{ EX. 2} & \multicolumn{9}{|c|}{ Scenario Number } \\
\hline & 1 & 2 & 3 & 4 & 5 & 6 & 7 & 8 & 9 \\
\hline$Y_{1}:$ & 63.9978 & 58.2045 & 64.0031 & 58.1772 & 64.018 & 64.0033 & 64.0083 & 58.1924 & 64.0155 \\
\hline$Y_{2}:$ & 13972.03 & 13977.4 & 13972.9 & 13971.1 & 13976.5 & 13972.9 & 13974.1 & 74.7 & 13975.6 \\
\hline$Y_{3}:$ & 30938 & 30926 & 30936 & 30940 & 30928 & 30936 & 30933 & 30932 & 30930 \\
\hline & 10 & 11 & 12 & 13 & 14 & 15 & 16 & 17 & 18 \\
\hline$Y_{1}:$ & 64.0086 & 58.193 & 64.0049 & 64.0211 & 58.1965 & 58.1962 & 58.1867 & 58.1948 & 64.0268 \\
\hline$Y_{2}:$ & 13934.28 & 13934.7 & 13933.38 & 13936.9 & 13935.6 & 13935.63 & 13933.38 & 13935.17 & 13938.31 \\
\hline$Y_{3}:$ & 30933 & 30932 & 30935 & 30927 & 30930 & 30930 & 30935 & 30931 & 30924 \\
\hline & 19 & 20 & 21 & 22 & 23 & 24 & 25 & 26 & 27 \\
\hline$Y_{1}:$ & 64.0168 & 64.0149 & 63.9959 & 64.0246 & 64.0293 & 58.1956 & 58.1881 & 58.1914 & 58.1934 \\
\hline$Y_{2}:$ & 13936.07 & 13935.6 & 13931.59 & 13937.8 & 13937.8 & 13935.18 & 13933.8 & 13934.7 & 13934.7 \\
\hline$Y_{3}:$ & 30929 & 30930 & 30939 & 30925 & 30923 & 30931 & 30934 & 30932 & 30932 \\
\hline & 28 & 29 & 30 & 31 & 32 & 33 & 34 & 35 & 36 \\
\hline$Y_{1}:$ & 63.9916 & 64.0197 & 58.193 & 64.0136 & 64.0188 & 64.0143 & 64.0096 & 64.0132 & 63.9917 \\
\hline$Y_{2}:$ & 13930.7 & 13936.5 & 13934.7 & 13935.2 & 13936.5 & 13935.6 & 13934.73 & 13935.2 & 13930.6 \\
\hline$Y_{3}:$ & 30941 & 30928 & 30932 & 30931 & 30928 & 30930 & 30932 & 30931 & 30941 \\
\hline
\end{tabular}




\subsection{Data Envelopment Analysis}

In order to compare the true efficiency of the scenarios, as mentioned, DEA was applied on simulation results. For years, DEA has been considered as one of the most well-known methods for measuring the relative efficiency of similar units. DEA technique has different advantages such as considering various inputs and outputs. DEA is a mathematical method of performance assessment for homogeneous decision making units (DMUs). DEA has been successfully implemented to evaluate different kinds of DMUs such as scenarios, in recent years.

With our simulation based optimization approach, the selection of a sequence is based on both cycle time and cost minimization and not just throughput maximization, as this method filters all the feasible scenarios utilizing DEA technique. Based on this DEA approach, each scenario is treated as a DMU, this is characterized by inputs and output.

The data were obtained from the proposed scenarios implementation. In this analysis, two inputs and one output are employed. The inputs are average $S_{2}$ cycle time and average cost. Average cost covers machining, tooling and preventive maintenance cost within simulation period linking the robotic cell's production process. The value of average $\mathrm{S}_{2}$ cycle time has been calculated as a proxy to the time between two successive produced parts. All these items are the main objectives in productivity process to be minimized in the considered robotic cell. Like other studies, it is typical to use cost and cycle time as inputs. In terms of the output, the number of produced throughput during simulation period has been accepted as output. Through DEA, scenarios are filtered via BCC model and only the efficient ones are selected.

Here, we considered each scenario as a DMU, since their inputs and outputs are the same type. Then by applying the model first developed by Banker, Charnes and Cooper called BCC model the efficiency of each scenario is calculated. They formulated their efficiency model for $n$ unit decision maker with $m$ input and $s$ output as a ratio of a weighted sum of outputs to a weighted sum of inputs. The efficiency of unit zero is a fractional linear program as shown in Eq. (4), where $u_{r}$, and $v_{i}$ are the weights to be applied to the outputs and inputs and $w$ is a free variable. Therefore, by applying DEA technique, the proposed scenarios are compared. We have the BCC Ratio Model (Input Orientation) for $n$ DMU as follows in Eq. (4).

S.t.

$$
\max E_{0}=\frac{\sum_{r=1}^{S} u_{r} y_{r 0+W}}{\sum_{i=1}^{m} v_{i} x_{i 0}}
$$

$$
\begin{array}{cl}
\frac{\sum_{r=1}^{s} u_{r} y_{r j+W}}{\sum_{i=1}^{m} v_{i} x_{i j}} \leq 1 & j=1,2, \ldots \ldots, n \\
& w ; \text { free variable } \\
u_{r} \geq \varepsilon & r=1,2, \ldots \ldots, s \\
v_{i} \geq \varepsilon & i=1,2, \ldots \ldots, m \\
W: \text { free } &
\end{array}
$$

Based on computations by Lingo, the results for the desired cases are shown in Table V.

It is evident that higher efficiency indicates the better scenarios. We define DMUs with efficiency value equals to ' 1 ' as efficient DMUs (scenarios).

Therefore, scenarios with numbers ' 4 ' and ' 6 ' in Example 1 and scenarios with numbers ' 4 'and '36' will be helpful as part sequencing for the designated Examples in two-machine robotic cell under $S_{2}$. Concerning the above revealed, in Example 1, sequence in the order of Blue-Purple-Red when Blue or Red part is the first one to be produced on the second machine, for these three different part types, robotic cell under $S_{2}$ is preferred than the other scenarios. In these optimal scenarios, although average $S_{2}$ cycle time in scenario ' 4 ' is not equal to average $S_{2}$ cycle time in scenario ' 6 ', production cost based on both scenarios is the same. Furthermore, throughput production during observation period for both scenarios is 
alike. For the six different part types problem in a robotic cell under $S_{2}$ (Example 2), the optimal cyclic sequences are sequence 1 in the order of Purple-Red-Yellow-Blue-GreenSilver when Green part is the first part to be produced on the second machine and sequence 6 in the order of Blue-Purple-Silver-Yellow-Green-Red when the first part to be produced on second machine is Silver. Scenario '4' with 58.1772 value has smaller average $\mathrm{S}_{2}$ cycle time in comparison with 63.9917 time units for scenario ' 36 '. On the contrary, production cost in scenario ' 36 ' is less than that of scenario ' 4 '. Output rate during observation period for scenario ' 4 ' is 30940 versus 30941 in scenario ' 36 '.

Table V: Scenarios PFMs based on the BCC model for the Examples.

\begin{tabular}{|c|c|c|c|c|c|c|c|c|c|}
\hline \multirow[t]{2}{*}{$\begin{array}{c}\mathbf{E X} . \\
1\end{array}$} & \multicolumn{9}{|c|}{$\begin{array}{c}\text { Scenario Number } \\
\text { Efficiency scores }(E S) \text { (Below comes) }\end{array}$} \\
\hline & 1 & 2 & 3 & 4 & 5 & 6 & 7 & 8 & 9 \\
\hline$E S$ & 0.8603 & 0.8608 & 0.9981 & 1 & 0.815 & 1 & 0.9991 & 0.9987 & 0.9991 \\
\hline \multirow[t]{2}{*}{$\begin{array}{c}\text { EX. } \\
2\end{array}$} & \multicolumn{9}{|c|}{$\begin{array}{c}\text { Scenario Number } \\
\text { Efficiency scores }(E S) \text { (Below comes) }\end{array}$} \\
\hline & 1 & 2 & 3 & 4 & 5 & 6 & 7 & 8 & 9 \\
\hline$E S$ & 0.9969 & 0.999 & 0.9868 & 1 & 0.9963 & 0.9968 & 0.9966 & 0.9995 & 0.9964 \\
\hline & 10 & 11 & 12 & 13 & 14 & 15 & 16 & 17 & 18 \\
\hline$E S$ & 0.9995 & 0.9998 & 0.9996 & 0.9991 & 0.9997 & 0.9997 & 0.9999 & 0.9997 & 0.9989 \\
\hline & 19 & 20 & 21 & 22 & 23 & 24 & 25 & 26 & 27 \\
\hline$E S$ & 0.9992 & 0.9993 & 0.9998 & 0.9989 & 0.9989 & 0.9997 & 0.9999 & 0.9998 & 0.9998 \\
\hline & 28 & 29 & 30 & 31 & 32 & 33 & 34 & 35 & 36 \\
\hline$E S$ & 0.9999 & 0.9992 & 0.9998 & 0.9993 & 0.9992 & 0.9993 & 0.9994 & 0.9993 & 1 \\
\hline
\end{tabular}

\section{CONCLUSION}

This study totally aimed to demonstrate an effective and reliable model by simulation based optimization approach to determine the sequencing in an unreliable two-machine robotic cell under $\mathrm{S}_{2}$ cycle, which produces different parts. By finding the best scenarios for the entry of components into the manufacturing cell, minimizing the time and operating costs simultaneously is possible. With respect to the above-mentioned suggested scenarios and comparison based DEA among them in designated Examples, it was concluded that scenarios coded as No. 4 and No. 6 in Example 1 and No. 4 and No. 36 in Example 2 are selected as the best amongst feasible proposals in such a way that minimum cycle time and operating cost is concurrently attainable.

The present study can allow modelling of various scenarios to be examined in future simulations with less expense, time and resources than experimentation with the real world system. Therefore, improvement of the manufacturing system before or during production will be conceivable. Moreover, optimal sequencing of parts by considering producing different parts in the robotic manufacturing cell including $m$ machines can be another topic for future research.

\section{REFERENCES}

[1] Hoogeveen, H. (2005). Multicriteria scheduling, European Journal of Operational Research, Vol. 167, No. 3, 592-623, doi:10.1016/j.ejor.2004.07.011

[2] Nidhiry, N. M.; Saravanan, R. (2014). Scheduling optimization of a flexible manufacturing system using a modified NSGA-II algorithm, Advances in Production Engineering \& Management, Vol. 9, No. 3, 139-151, doi:10.14743/apem2014.3.183

[3] Lv, Y.; Zhang, J.; Qin, W. (2017). A genetic regulatory network-based sequencing method for mixed-model assembly lines, Advances in Production Engineering \& Management, Vol. 12, No. 1, 62-74, doi: $\underline{10.14743 / \mathrm{apem} 2017.1 .240}$ 
[4] Gultekin, H.; Akturk, M. S.; Karasan, O. E. (2010). Bicriteria robotic operation allocation in a flexible manufacturing cell, Computers \& Operations Research, Vol. 37, No. 4, 779-789, doi:10.1016/j.cor.2009.06.025

[5] Feng, J.; Che, A.; Wang, N. (2014). Bi-objective cyclic scheduling in a robotic cell with processing time windows and non-Euclidean travel times, International Journal of Production Research, Vol. 52, No. 9, 2505-2518, doi:10.1080/00207543.2013.849015

[6] Kayan, R. K.; Akturk, M. S. (2005). A new bounding mechanism for the CNC machine scheduling problems with controllable processing times, European Journal of Operational Research, Vol. 167, No. 3, 624-643, doi:10.1016/j.ejor.2004.07.012

[7] Gurel, S.; Akturk, M. S. (2007). Considering manufacturing cost and scheduling performance on a CNC turning machine, European Journal of Operational Research, Vol. 177, No. 1, 325-343, doi:10.1016/j.ejor.2005.11.029

[8] Sethi, S. P.; Sriskandarajah, C.; Sorger, G.; Blazewicz, J.; Kubiak, W. (1992). Sequencing of parts and robot moves in a robotic cell, International Journal of Flexible Manufacturing Systems, Vol. 4, No. 3-4, 331-358, doi:10.1007/BF01324886

[9] Fathian, M.; Kamalabadi, I. N.; Heydari, M.; Farughi, H.; Naseri, F. (2013). Applying metaheuristic algorithms for output rate analysis in two-machine robotic manufacturing cells, International Journal of Advanced Robotic Systems, Vol. 10, No. 3, Paper 169, 11 pages, doi: $10.5772 / 56051$

[10] Dawande, M.; Geismar, H. N.; Sethi, S. P.; Sriskandarajah, C. (2005). Sequencing and scheduling in robotic cells: recent developments, Journal of Scheduling, Vol. 8, No. 5, 387-426, doi:10.1007/s10951-005-2861-9

[11] Geismar, H. N.; Pinedo, M. (2010). Robotic cells with stochastic processing times, IIE Transactions, Vol. 42, No. 12, 897-914, doi:10.1080/0740817X.2010.491505

[12] Al-Salem, M.; Haouari, M.; Kharbeche, M.; Khallouli, W. (2016). A free-slack-based genetic algorithm for the robotic cell problem with controllable processing times, Rabadi, G. (Ed.), Heuristics, Metaheuristics and Approximate Methods in Planning and Scheduling, 77-93, Springer International Publishing, Cham, doi:10.1007/978-3-319-26024-2_4

[13] Gultekin, H.; Tula, A.; Akturk, M. S. (2016). Automated robotic assembly line design with unavailability periods and tool changes, European Journal of Industrial Engineering, Vol. 10, No. 4, 499-526, doi:10.1504/EJIE.2016.078142

[14] Kise, H.; Shioyama, T.; Ibaraki, T. (1991). Automated two-machine flowshop scheduling: a solvable case, IIE Transactions, Vol. 23, No. 1, 10-16, doi:10.1080/07408179108963836

[15] Logendran, R.; Sriskandarajah, C. (1996). Sequencing of robot activities and parts in twomachine robotic cells, International Journal of Production Research, Vol. 34, No. 12, 34473463, doi: $10.1080 / 00207549608905099$

[16] Aneja, Y. P.; Kamoun, H. (1999). Scheduling of parts and robot activities in a two machine robotic cell, Computers \& Operations Research, Vol. 26, No. 4, 297-312, doi:10.1016/S03050548(98)00063-X

[17] Batur, G. D.; Erol, S.; Karasan, O. E. (2016). Robot move sequence determining and multiple part-type scheduling in hybrid flexible flow shop robotic cells, Computers \& Industrial Engineering, Vol. 100, 72-87, doi:10.1016/j.cie.2016.08.006

[18] Hall, N. G.; Kamoun, H.; Sriskandarajah, C. (1997). Scheduling in robotic cells: classification, two and three machine cells, Operations Research, Vol. 45, No. 3, 421-439, doi:10.1287/opre.45.3.421

[19] Abdekhodaee, A. H.; Wirth, A.; Gan, H.-S. (2006). Scheduling two parallel machines with a single server: the general case, Computers \& Operations Research, Vol. 33, No. 4, 994-1009, doi:10.1016/j.cor.2004.08.013

[20] Paul, H. J.; Bierwirth, C.; Kopfer, H. (2007). A heuristic scheduling procedure for multi-item hoist production lines, International Journal of Production Economics, Vol. 105, No. 1, 54-69, doi:10.1016/j.ijpe.2005.11.008

[21] Wen, C.; Ekşioğlu, S. D.; Greenwood, A.; Zhang, S. (2010). Crane scheduling in a shipbuilding environment, International Journal of Production Economics, Vol. 124, No. 1, 40-50, doi:10.1016/j.ijpe.2009.09.006 
[22] Abdulkader, M. M. S.; ElBeheiry, M. M.; Afia; N. H.; El-Kharbotly, A. K. (2013). Scheduling and sequencing in four machines robotic cell: Application of genetic algorithm and enumeration techniques, Ain Shams Engineering Journal, Vol. 4, No. 3, 465-474, doi:10.1016/j.asej.2012.11.002

[23] Lei, W.; Che, A.; Chu, C. (2014). Optimal cyclic scheduling of a robotic flowshop with multiple part types and flexible processing times, European Journal of Industrial Engineering, Vol. 8, No. 2, 143-167, doi:10.1504/EJIE.2014.060434

[24] Batur, G. D.; Erol, S. (2016). Using simulated annealing for flexible robotic cell scheduling, Gazi University Journal of Science, Vol. 29, No. 3, 573-582

[25] Savsar, M.; Aldaihani, M. (2008). Modeling of machine failures in a flexible manufacturing cell with two machines served by a robot, Reliability Engineering \& System Safety, Vol. 93, No. 10, 1551-1562, doi:10.1016/j.ress.2007.06.002

[26] Hamasha, M. M.; Alazzam, A.; Hamasha, S.; Aqlan, F.; Almeanazel, O.; Khasawneh, M. T. (2015). Multimachine flexible manufacturing cell analysis using a Markov chain-based approach, IEEE Transactions on Components, Packaging and Manufacturing Technology, Vol. 5, No. 3, 439-446, doi:10.1109/TCPMT.2015.2394232

[27] Akturk, M. S.; Gultekin, H.; Karasan, O. E. (2005). Robotic cell scheduling with operational flexibility, Discrete Applied Mathematics, Vol. 145, No. 3, 334-348, doi:10.1016/j.dam.2004.02.012

[28] Akturk, M. S.; Gurel, S. (2007). Machining conditions-based preventive maintenance, International Journal of Production Research, Vol. 45, No. 8, 1725-1743, doi:10.1080/00207540600703587

[29] Batur, G. D.; Karasan, O. E.; Akturk, M. S. (2012). Multiple part-type scheduling in flexible robotic cells, International Journal of Production Economics, Vol. 135, No. 2, 726-740, doi:10.1016/j.ijpe.2011.10.006

[30] Pidd, M. (1986). Computer Simulation in Management Science, reprinted with corrections, Wiley, Chichester

[31] Yang, B.; Chen, W.; Lin, C. (2017). The algorithm and simulation of multi-objective sequence and balancing problem for mixed mode assembly line, International Journal of Simulation Modelling, Vol. 16, No. 2, 357-367, doi:10.2507/IJSIMM16(2)CO10

[32] Lora, F. A.; Boff, U.; Yurgel, C. C.; Folle, L. F.; Schaeffer, L. (2013). Validation of the computer simulation process applied to the incremental forming process for the evaluation of strain paths, Key Engineering Materials, Vol. 554-557, 2453-2461, doi:10.4028/www.scientific.net/KEM.554-557.2453

[33] Nie, X. D.; Chen, X. D.; Chen, X. (2016). Simulation study of flexible manufacturing cell based on token-oriented Petri net model, International Journal of Simulation Modelling, Vol. 15, No. 3 , 566-576, doi:10.2507/IJSIMM15(3)CO14

[34] Supsomboon, S.; Varodhomwathana, T. (2017). Robot and plant simulation for automotive part production process design: A case study, International Journal of Simulation Modelling, Vol. 16, No. 4, 617-629, doi:10.2507/IJSIMM16(4)5.397

[35] Negahban, A.; Smith, J. S. (2014). Simulation for manufacturing system design and operation: literature review and analysis, Journal of Manufacturing Systems, Vol. 33, No. 2, 241-261, doi:10.1016/j.jmsy.2013.12.007 